\title{
IDL in Monterrey: science, art and culture of light
}

Perla Marlene Viera-González, Guillermo SánchezGuerrero

Perla Marlene Viera-González, Guillermo E. Sánchez-Guerrero, "IDL in Monterrey: science, art and culture of light

," Proc. SPIE 10741, Optics Education and Outreach V, 107410Q (14 September 2018); doi: 10.1117/12.2320308

SPIE Event: SPIE Optical Engineering + Applications, 2018, San Diego, California, United States 


\title{
IDL in Monterrey: science, art and culture of light
}

\author{
Perla Marlene Viera-González and Guillermo Ezequiel Sánchez-Guerrero \\ Universidad Autónoma de Nuevo León, Facultad de Ciencias Físico Matemáticas, Av. \\ Universidad S/N Ciudad Univertaria, 66455, San Nicolás de los Garza, México
}

\begin{abstract}
May 16th, 2018 was the first International Day of Light and the Universidad Autonoma de Nuevo Leon celebrated it with a project called "IDL in Monterrey: science, art and culture of light". The two main objectives of the project were: to offer guidance to basic education teachers about how to use hands-on activities related with light, optics, and photonics to teach science with low-cost materials and taking into account the application and impact of science in our daily light; and involve non-technical audience in the appreciation and learning of the sciences, technologies, and arts related to light, using artistic and scientific demonstrations and interactive activities. The project includes teacher training, science and art workshops, STEM exhibitions, theater play and talks about light and its importance in life, science, technology, art, and culture. The present work will include the outcomes of the event and the impact of the different activities carried out.
\end{abstract}

Keywords: IDL, International Day of Light, Optics Outreach, Outreach activities, Science education, Informal education, STEAM workshops, hands-on activities

\section{INTRODUCTION}

The success of the International Year of Light and Light-based Technologies 2015 (IYL2015) with its more than 13000 worldwide activities, that reached an audience over 100 million people, was only the first step of a global initiative that pursues to raise the awareness about the importance of Light, Optics and Photonics in the different aspects of daily life as: Science, Technology, Art and Culture.

In this regard, the celebration of the International Day of Light (IDL) on May 16th provides a crossdisciplinary educational and outreach project to improve the public understanding about light. The IDL goals include the understanding about the link between light and our daily lives, contribute with the science-oriented education in environments that take into account diversity and gender equity, exposing the link between light and art and culture, among others. ${ }^{1}$

This work presents the activities done and the outcomes obtained for the celebration of the IDL in Monterrey by the Universidad Autonoma de Nuevo Leon (UANL) and how different Science Outreach groups with different STEM outreach projects converge all its efforts to conduct a project that involves Science, Technology, Art, and Culture. The result was a project with different activities and different goals that create a link between basic-education teachers*, the general public, and scientists, including professors and science students. Besides, it established the foundations for new projects that will help to increase the awareness of Science, Light and Optics in Monterrey and, even, in Mexico.

Further author information: (Send correspondence to P.V.G.)

P.V.G.: E-mail: marlene.viera.gzz@gmail.com

${ }^{*}$ This is the equivalent of K12 teachers, it includes elementary and secondary schools teachers 


\section{SCIENCE OUTREACH GROUPS AND PROJECTS}

The Facultad de Ciencias Fisico Matematicas (FCFM) of the UANL has different groups dedicated to Science Outreach with different goals and fields of action. One of these groups is "Physics for everyone" (Fisica Pato2) that is in charge of the project "Optics for everyone" (Optica Pato2), whose objective is to increase the awareness of Light and Optics in Monterrey and the near cities with interactive activities, workshops, conferences and talks. This group was formed in 2013 by SPIE student members and, thanks to the support of the SPIE, performed 13 different events to celebrate the IYL2015 and reached more than 8,000 people. ${ }^{2}$ After 2015, the group increases its number of members (Fig 1), its scope, its number and quality of events and, especially, its number of collaborations with others groups. The partners of Physics for everyone are:

- Partners inside of the Universidad Autonoma de Nuevo Leon

- UANL Mobile Planetarium

- UANL Cultural Secretary (Cultura UANL)

- Student Outreach Group "Laniakea"

- Academic Outreach Group "Divertimatematicas"

- Outreach Group "Robotics FCFM - UANL"

- Theater Student Club "Laboratorio Kabblam FCFM"

- Digital Art Student Club (CAD FCFM)

- Make-up and especial effects Student Club

- IEEE Photonics Society UANL Student Chapter

- Partners in the state of Nuevo Leon

- Ministry of Education in Nuevo Leon (SEP N. L.)

- SPIE-OSA Instituto Tecnologico y de Estudios Superiores de Monterrey Student Chapter (SPIE-OSA ITESM Student Chapter)

- Partners in Mexico (country)

- National Network of Science Outreach Groups

- Universidad Autonoma de Zacatecas through the Science Outreach Group 'Quark'

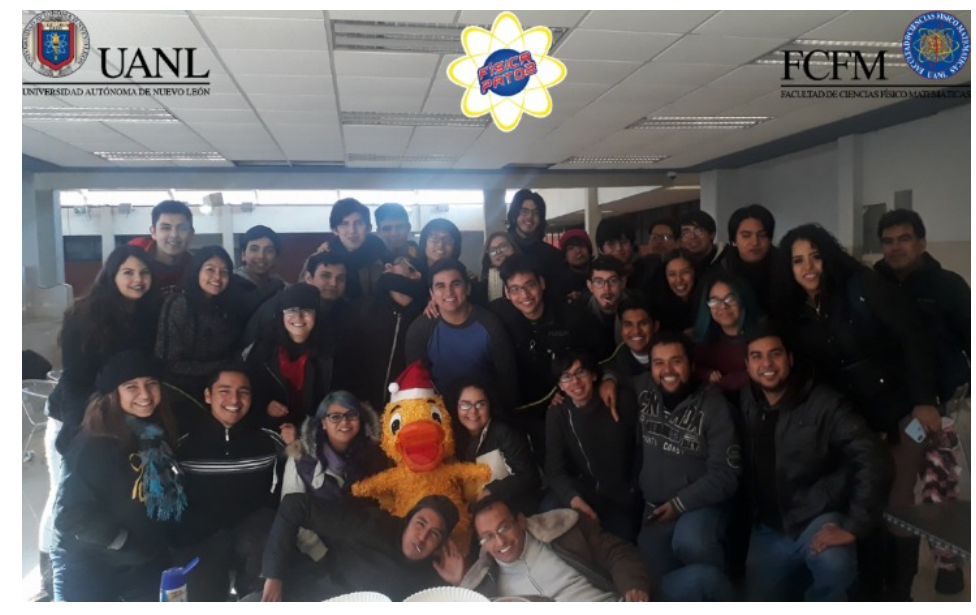

Figure 1. Some of the members of "Physics for everyone". 
Since 2016, Physics for everyone has been collaborating with Judy Donnelly, Nancy Magnani and Kathleen Robinson in the translation of the workshop "Dumpster Optics", which was partially presented in Mexico in 2017 during the 32nd National Meeting of Science Outreach Professionals. ${ }^{3}$

Also, since 2017, the group Physics for everyone is part of the Mexican Network of Science Outreach Groups "Recreacion en Cadena" (Red Mexicana de Talleristas de Ciencia Recreacion en Cadena). Among the different projects of the network, it is important to highlight the project "Suma Ciencia", that consists in simultaneous public events in different cities of Mexico where, every two months, Science outreach professionals organize experiments, demonstrations and workshops related with a specific science topic. The impact of this project is such that the National Council of Science and Technology (CONACyT) support it for 2017 and 2018. ${ }^{4}$

For the IDL in Monterrey, the group Physics for everyone in collaboration with all its partners and aligning the projects "Suma Ciencia" and "Dumpster Optics" with the IDL objectives, proposed a multidisciplinary project with different activities that allows basic-education teachers, families and, the general public to be part of a scientific, artistic and cultural event for celebrating the Light. This project called "IDL in Monterrey: science, art and culture of light", was supported by the International Society for Optics and Photonics and took place in "Colegio Civil Centro Cultural Universitario" (Monterrey Center) during May 19th, 2018. The figure 2 shows one of the first images that was shared for the advertising of the project.

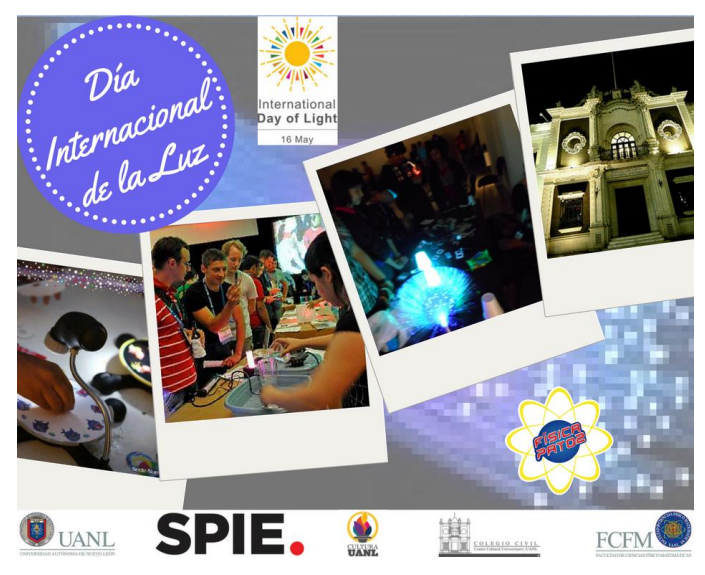

Figure 2. Advertising used during the project planning.

\section{THEORETICAL BACKGROUND}

For the planning and execution of the event, it was necessary to take into account some essential concepts related to science, education and outreach. The learning of concepts is not the primary objective of the proposed project and, besides, is not the only objective while learning science. As in any science education project, "IDL in Monterrey" should include favorable conditions for the understanding and the appropriation of science, technology, art and culture of Light. ${ }^{2}$

The Merriam-Webster dictionary defines outreach as "the extending of services or assistance beyond current or usual limits" and as " the activity or process of bringing information or services to people." 5 Thus the concept of science outreach should be considered as a way to take science further away from its traditional spaces and typical audiences, take the science outside the labs and put it at the reach of all the people. Other definitions of science outreach include "a range of approaches and activities in which information flows from scientist to the public, from the public to scientists or between scientists and the public" ${ }^{6}$ allowing to include a different kind of activities to achieve the objective of the different science outreach events.

To establish the communication needed for the science outreach activities, it was necessary the implementation of the constructivism through a mechanism that links ideas, knowledge and experience. ${ }^{7,8}$ 
Considering the definitions of science outreach and having as objective the creation of a link between the audience and light, it was essential to define the type of activities we wanted to conduct to increase the awareness about Light, Optics and Science using the constructivism::2,7-10

- Demonstration. It is the act of showing some experiment or science phenomena with the minimal interaction of the audience. Its objective is to explain a concept and establish general ideas about a field.

- Interactive demonstration. It is an act where the audience see how some experiment or activity is performed and they have the chance to interact with it, but the audience is not in total charge of the activity. It also includes the exposition of concepts, but also includes the opportunity of the audience to experiment, to see "what happens if...?".

- Hands-on activity. It is to be actively and personally involved in the learning process, and it provides the direct practical experience of the concept or phenomena.

Generally, the demonstrations are activities that require specialized or not inexpensive equipment, and this is why are used only to demonstrate concepts, but allows the audience to see and formulate questions to establish a starting point. Later, with the interactive demonstrations, the public can formulate more questions, hypothesis and try them through supervised experiments. Finally, the hands-on activities offer the complementary experience of significant learning where the mechanicals actions and the emotions are combined..$^{2,7,8}$

The activities mentioned above can be included in a workshop if the objective is oriented to gain skills, or in an exhibition, where the display of multiple activities is desirable with the objective of engaging the public to Science in an informal environment.

When we talk about Science exhibitions, as "Suma Ciencia", or about a Science workshop, as "Dumpster Optics", we usually understand that Science, Technology, Engineering and Math (STEM) concepts, phenomena and activities will be involved. As the IDL shows the importance of Light in Science, Technology, Art and Culture, we need to integrate the "A" to the equation and use "STEAM" oriented activities where the audience can see that science, technology, art and creativity are related. Moreover, the STEAM activities are necessary because the hard sciences need to be complemented with creativity to solve problems and apply technical knowledge. Besides, the use of STEAM activities can support the labor of engaging more people in science, because it can be more enjoyable and meaningfully and, also, offers a more human side of science. ${ }^{11}$

\section{EVENT DESCRIPTION AND OUTCOMES}

The International Day of Light is May 16th, but the day of the week is a critical factor that can decrease the attendance; with this in mind, the project "IDL in Monterrey: science art, and culture of light" and its events were celebrated on May 19th, 2018 in a public and centric place: Colegio Civil Centro Cultural Universitario. The figure 3 show the press release used by "Cultura UANL" for the advertising of the IDL 2018 in the UANL.

The main objective of this project was to create awareness about the importance of Light and its impact in Science, Technology, Culture, Art and other every-day aspects through activities that can arouse the interest, especially of children and teenagers. Thus, it was important to find a way to involve the formal and informal environments where kids and youth learn: their families and the school. Thus the next specific objectives were defined:

- Teach elementary and secondary school teachers how they can use Optics and Photonics activities and lessons as part of their classes to teach Science more interactively and explaining that light is everywhere.

- Offer scientific, cultural and artistic activities where the families can interact with light and see its role in different aspects of their life.

For the above, it was fundamental to divide the project into two events: "Dumpster Optics Workshop" for teachers and, "Suma Ciencia" a Science exhibition for families and the general public. 


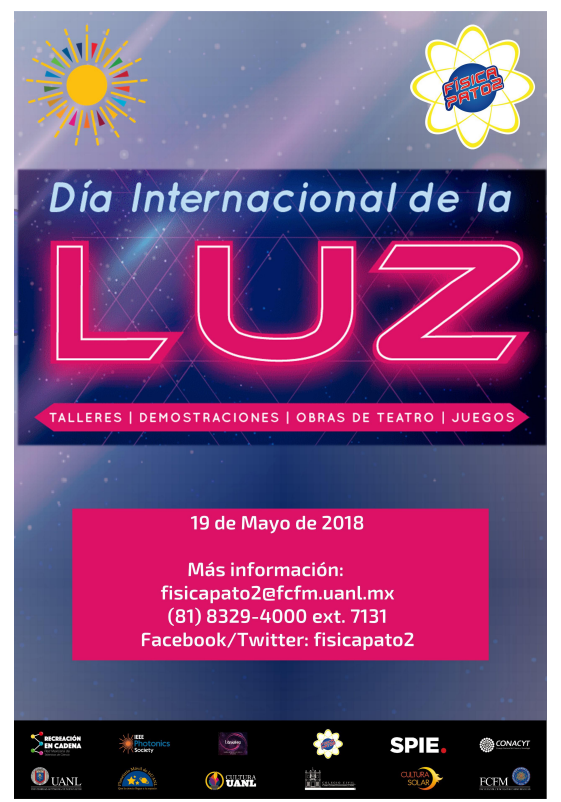

Figure 3. Press release about the IDL 2018 celebration by the UANL.

\subsection{DUMPSTER OPTICS WORKSHOP FOR BASIC-EDUCATION TEACHERS}

\subsubsection{Description}

"Dumpster Optics" is a project that consists in activities that use commonly available materials, re-purposed for use in optics; thus, any materials should cost no more than $\$ 2.00$ USD. This project has eight lessons available at no cost online (ww.lasertechonline.org):

- Light and shadows

- Making waves - The colors of Light

- Bending light - Reflection

- Bending light - Refraction

- Bending light - Diffraction

- Seeing color - Eyes and art

- Polarized light art

- What is a Laser?

Each of these lessons includes STEAM activities and have well-defined learning objectives with an interactive approach to the light phenomena involved. ${ }^{12}$

The workshop "Dumpster Optics" was selected how the ideal activity to teach basic education teachers how to use hands-on activities related to Optics and Photonics as part of their Science courses and involve their students in the active learning of science. The publicity designed for this workshop is shown in figure 4 .

For our project, the challenge was to adapt the materials to the Mexican market and obtain the materials needed for a workshop with 40 teachers. Besides, the translation of the course notes and its inclusion in a printed booklet was performed. 


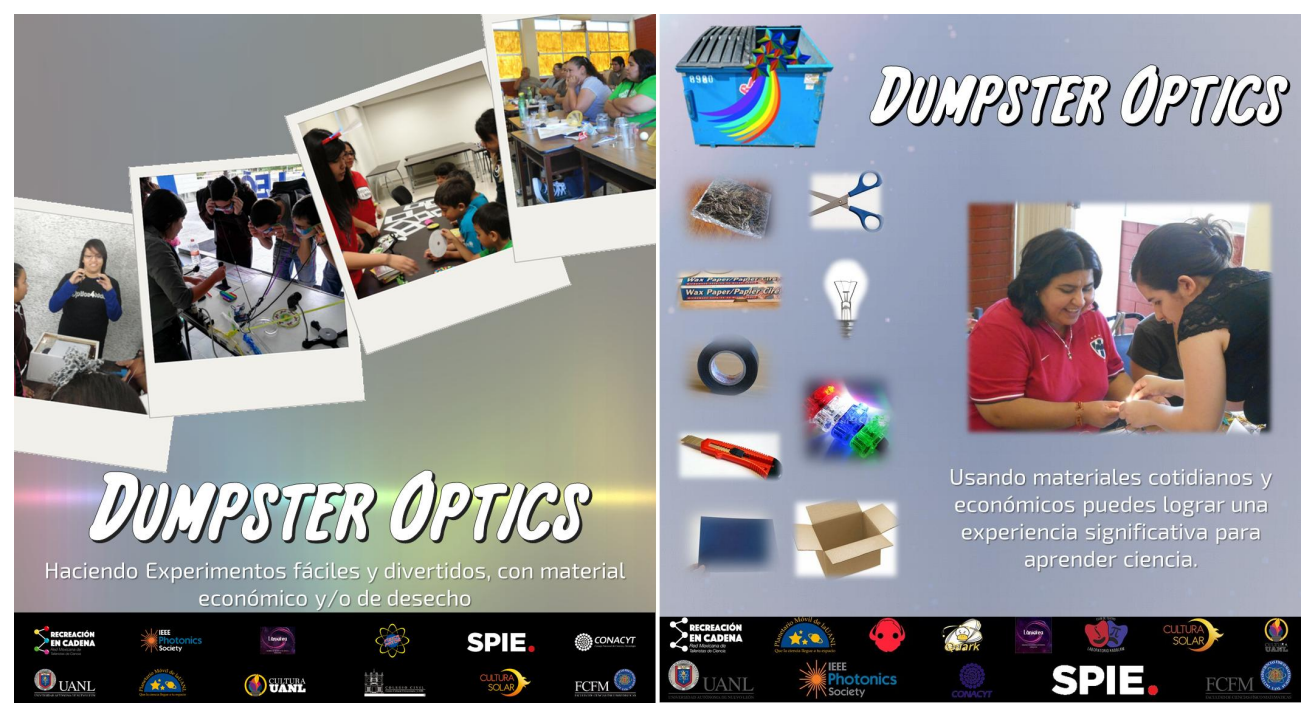

Figure 4. Left: Official advertising of the "Dumpster Optics" workshop. Right: Advertising used to explain that, only using the materials shown in the picture the lesson "Light and shadows" can be taught.

The teachers that attended to the workshop were selected due to their previous interest in Science activities and thanks to the support of the Science and Technology department of the Ministry of Education in the State of Nuevo Leon (SEP N.L.). Each one of them received a free booklet with the course notes and a bag with most of the material needed for all the activities.

\subsubsection{Outcomes}

In summary, the results of the workshop were (Fig. 5):

- A one-day workshop of 4 hours or more, is not enough to cover the basic concepts of the eight lessons. This first edition of the workshop could be considered as an introduction about how to use "dumpster" materials to do experiments.

- The ideal distribution of the workshop, according to the teachers, is sessions of 3 hours or less and, in each session, cover only 1 or 2 of the lessons.

- The teachers believed that they would need a science background to understand the topics included in the workshop but, in the end, they found that the workshop was introductory and easy to follow.

- Almost all the activities could be (partially) adapted to kids of different ages because it offers the application of the scientific method and the observation of natural phenomena as part of the learning process.

- Some the lessons that include art-related activities could be used as school art projects.

- The optics related demonstrations are attractive to catch the attention of kids, teenagers and adults (teachers).

- The classroom can be transformed into a lab without the use of some specialized equipment.

- All the teachers enjoyed the workshop and are interested in a second session to cover all the missing lessons and try new ideas 


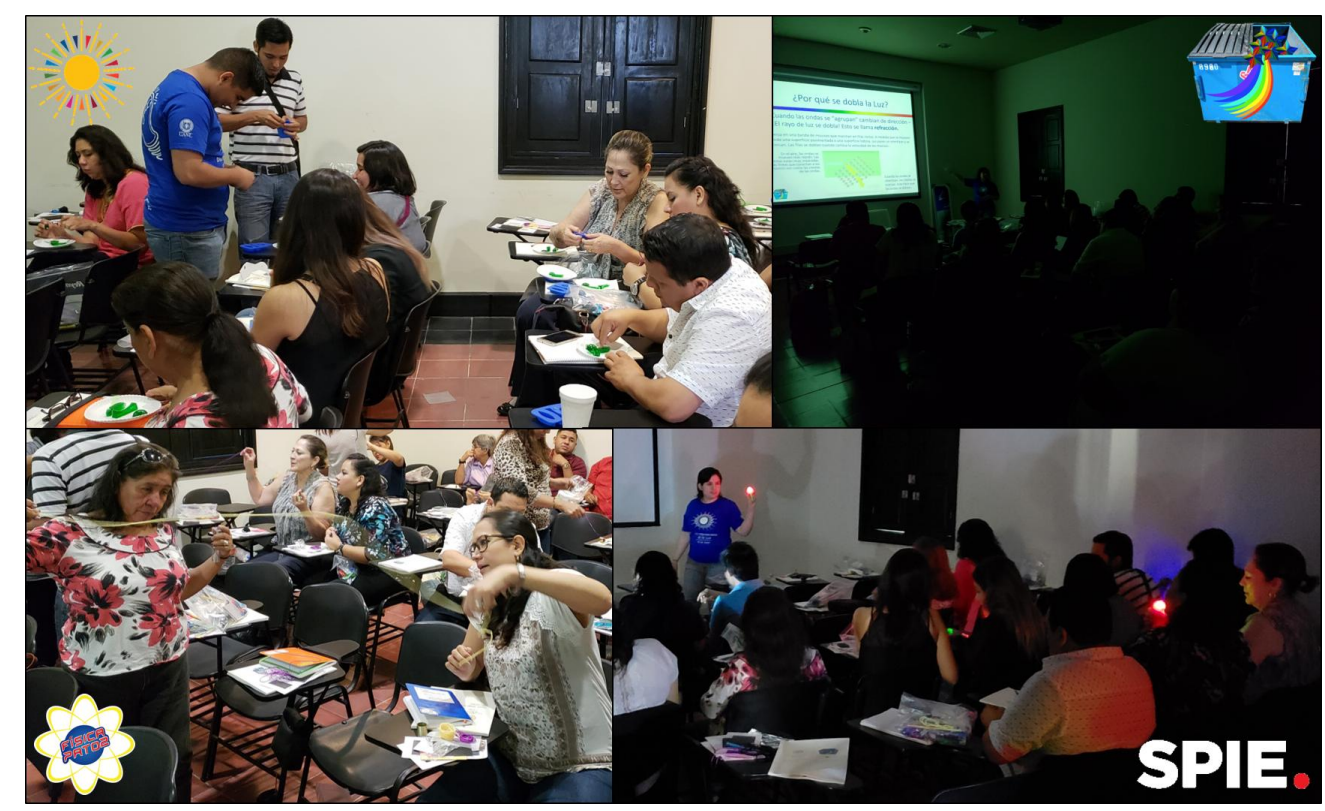

Figure 5. Teachers during the "Dumpster optics" workshop.

\subsection{Suma Ciencia - Public event}

The Mexican Network of Science Outreach Groups "Recreacion en Cadena" has as main objective the professionalization of groups and people doing Science Outreach in Mexico and increase the number of actions of the Science Outreach Workshops and its impact in our country. With this in mind, the project "Suma Ciencia" was developed, looking for free public events in simultaneous places in different cities throughout the country, where the families can participate in scientific activities. ${ }^{4}$

These events have a different topic in every edition and, to celebrate the IDL2018, the topic for the 7th edition was "Light". In Monterrey, this event is in charge of the FCFM - UANL, through the groups "Physics for everyone" and "UANL Mobile Planetarium" and was officially called "Suma Ciencia - IDL in Monterrey", the advertising of the event is shown in figure 6 .

\subsubsection{Description}

For "Suma Ciencia - IDL in Monterrey" the next activities were included:

- Hands-on activties

- Kaleidoscope construction

- Fake 3D

- Ghost Pepper Pyramid

- Pinhole viewer

- Newton disc

- Solar system construction

- Science interactive demonstrations

- What is light? by Physics for everyone

- Luminicesce by IEEE Photonics Society UANL Student Chapter

- Light phenomena by SPIE-OSA ITESM Student Chapter 


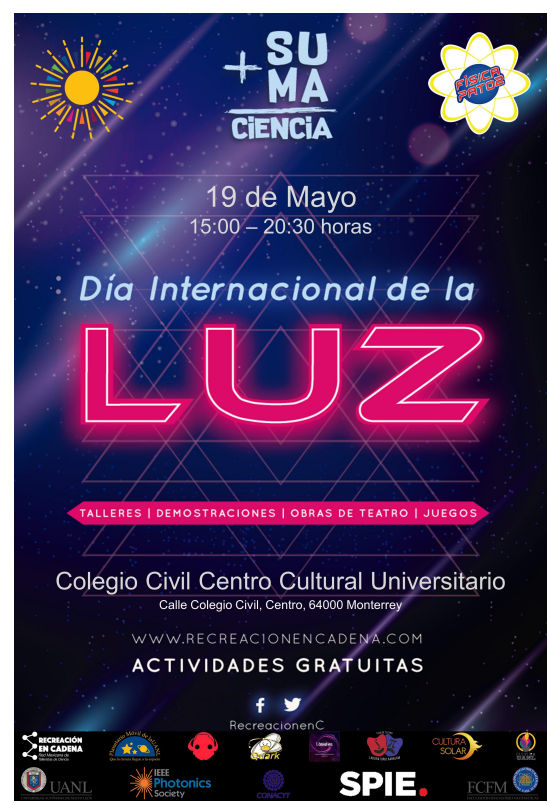

Figure 6. "Suma Ciencia - IDL in Monterrey" advertsing.

- Playing with waves by Quark

- Learning about the space by Laniakea

- Science demonstrations

- Solar observation

- Mobile planetarium

- Cultural activities

- Play "The Light is off..."

- The life of Ligth scientist

- Mimes explaining ligth-experiments

- Tematic face painting

- Interactive artistic demonstrations

- Light painting

- 3D-color mural display

- Polarized art

- Complementary science outreach activities by the "Divertimatematicas" and "Robotics FCFM - UANL"

The science activities were divided into three types, according to section 3: the solar observation and the explanations about our solar system inside of the mobile planetarium, allowed the audience to learn about astronomy in a not very interactive way, but using attractive topics, the stars and our universe (Fig. 7). For learning more concepts related with Optics, Photonics and Astrophysics the interactive demonstrations by Physics for everyone, SPIE-OSA Student chapter, Quark and Laniakea offered in total more than 60 minutes of experiments and interactive activities (Fig. 8). Finally, for a complete experience, the hands-on activities let the audience to learn about phenomena and build something to keep during the process of learning. These 

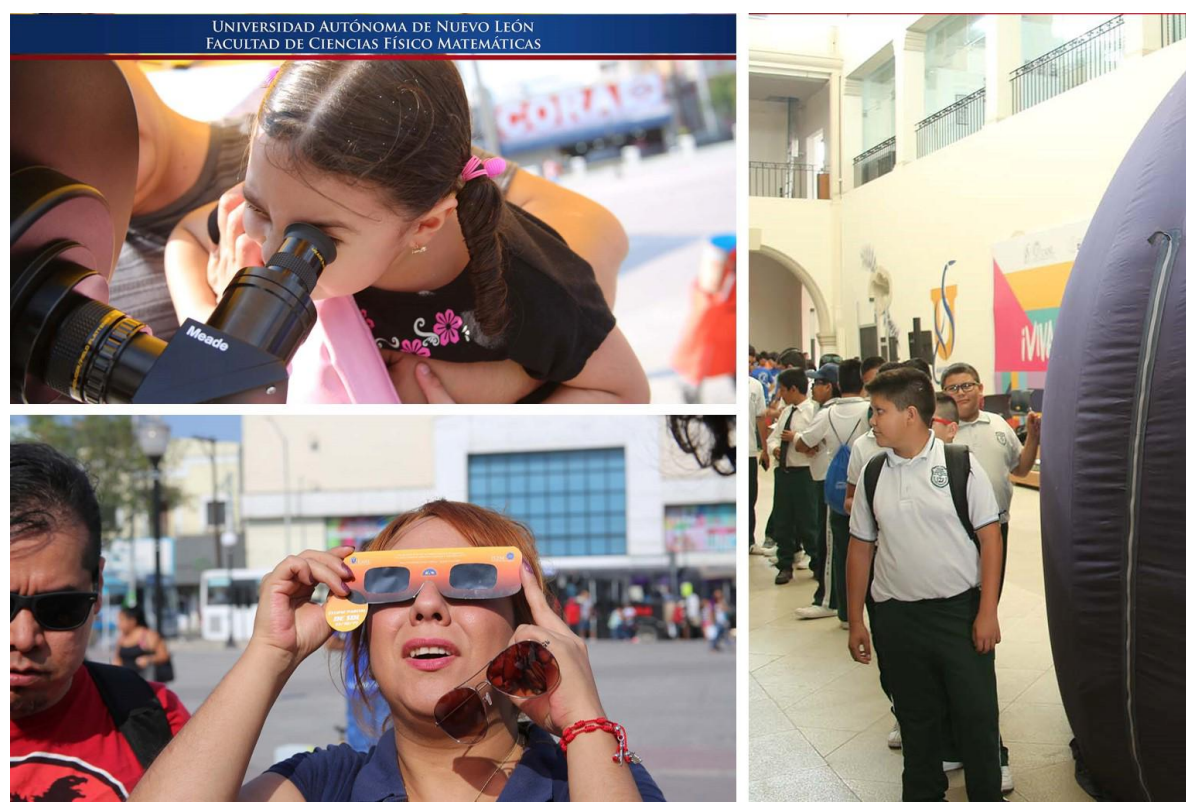

Figure 7. Solar observation, telescopes and mobile planetarium.
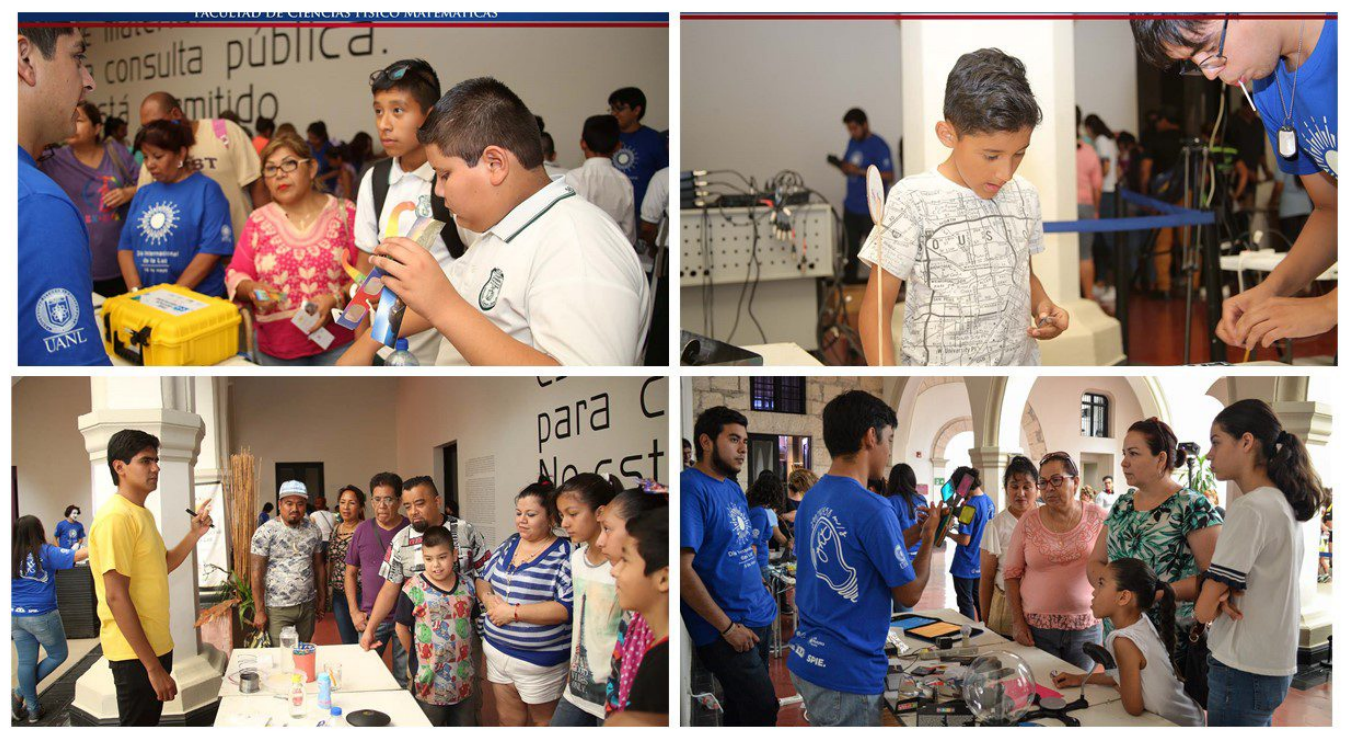

Figure 8. Scientific demonstrations performed by ITESM Student Chapter, Laniakea, Quark and Physics for everyone.

hands-on activities can be considered as STEAM activities because it is not only about science, it implies the use of creativity and the act of art appreciation (Fig. 9).

The cultural activities had the objective of explaining in an informal and non-scientific way some important scientific facts and phenomena. The first activity was the play "The Light is off...", where a family learns, through several incidents in their day, the importance and impact of Light in their lives. Further, the life of scientists like Einstein, Newton, Tesla, Curie, Franklin, Edison and Sagan, and their contributions to science and their works in Optics, Photonics, Electromagnetism and Modern Physics were explained using plush and finger puppets that allow the audience to interact with this celebrities directly. Also, as a way to catch the attention of the pedestrians, mimes and students doing pantomimes play with the audience doing science experiments and 


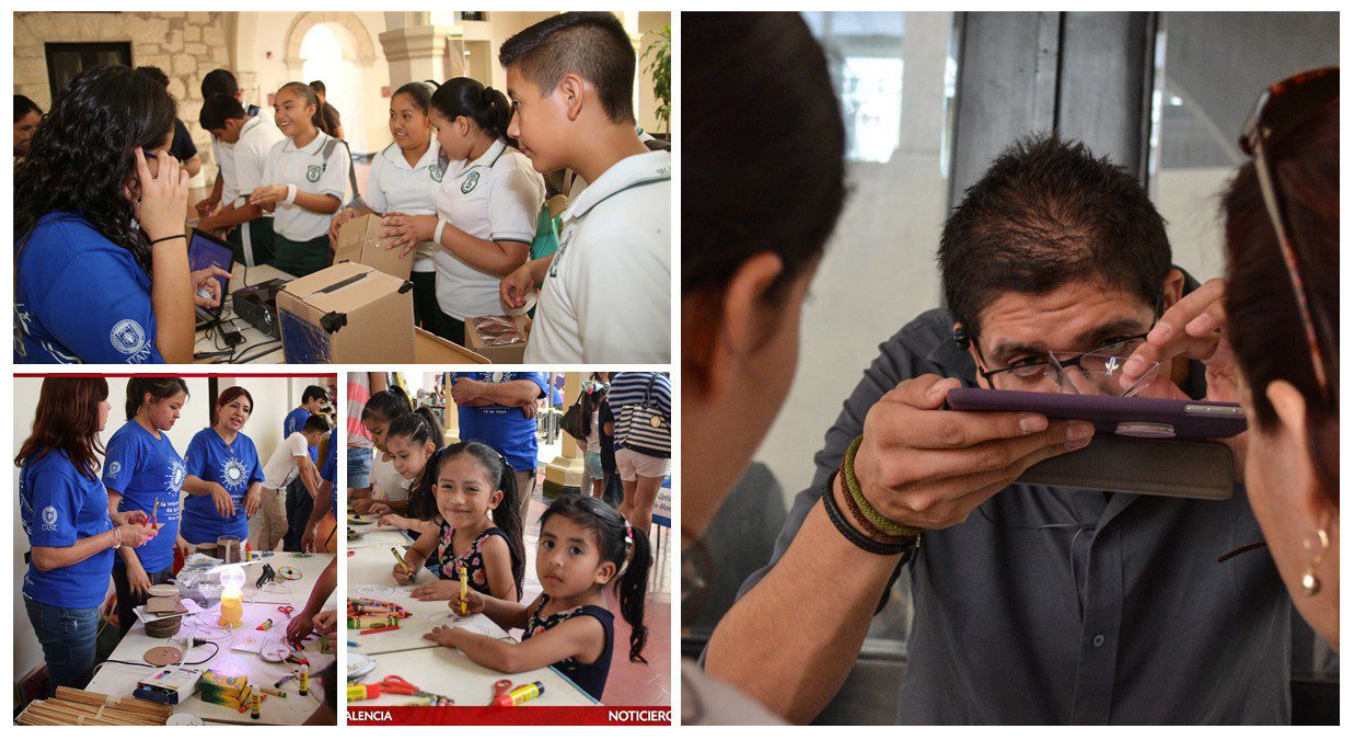

Figure 9. Hands-on activities: pinhole viewer construction, Newton's disc and pepper ghost pyramid.

explaining it. Finally, for the small children, an activity of face painting was offered, and during it, the children were asked about the things they like, about school and science-related topics with the objective of recommended to them the next activities where they could have fun. Some of these activities are shown in figure 10.
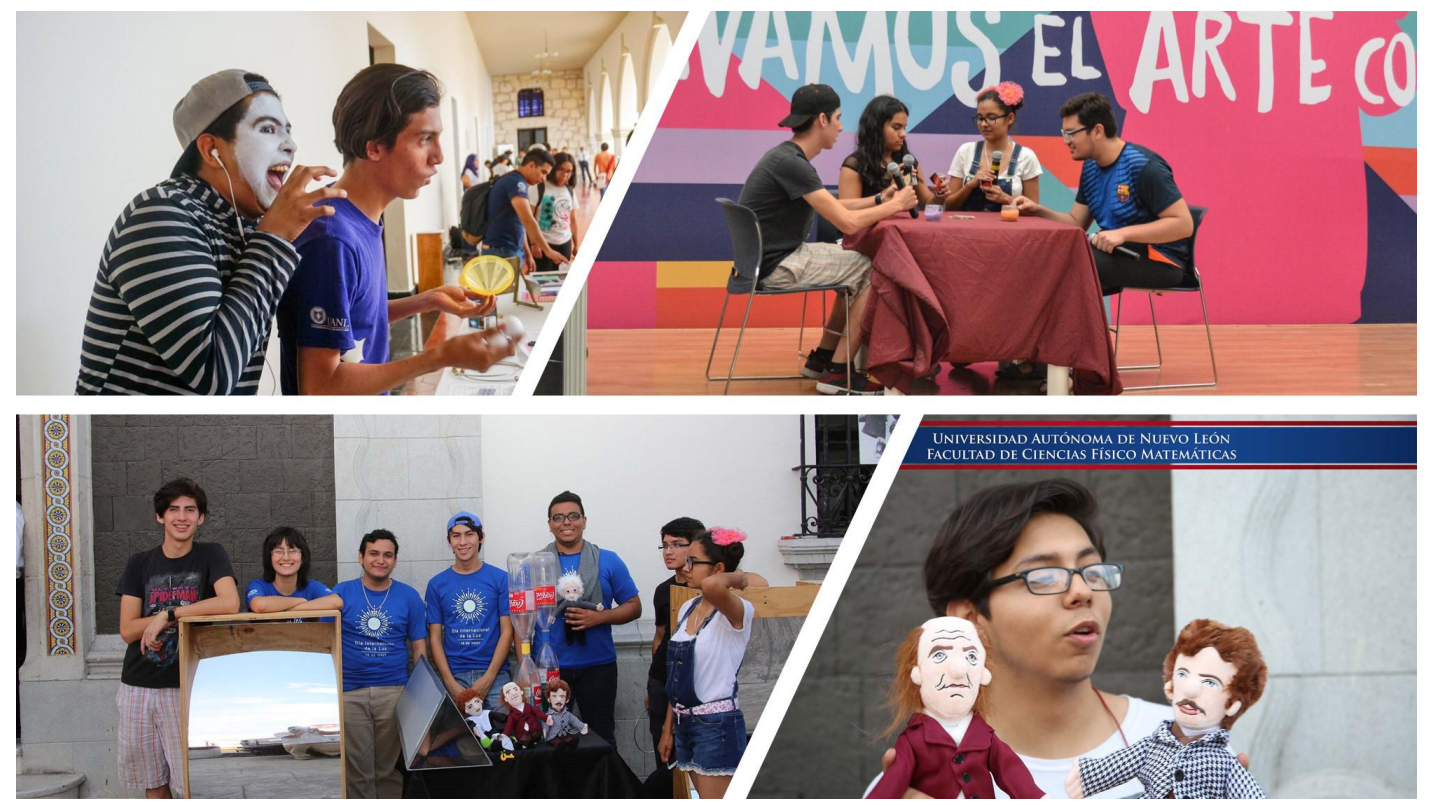

Figure 10. Cultural activities: mimes, play "The Light is off..." and plush scientists.

In addition to the cultural activities, the interactive artistic demonstrations allow the audience to see and interact with art thanks to the use of science, as is the case of light painting (Fig. 11), the use of chromatic aberration lenses for 3D illusions (Chromadepth ${ }^{\circledR}$, see Fig. 12) and the creation of small artistic pieces with cellophane and polarizers (Fig. 13). 


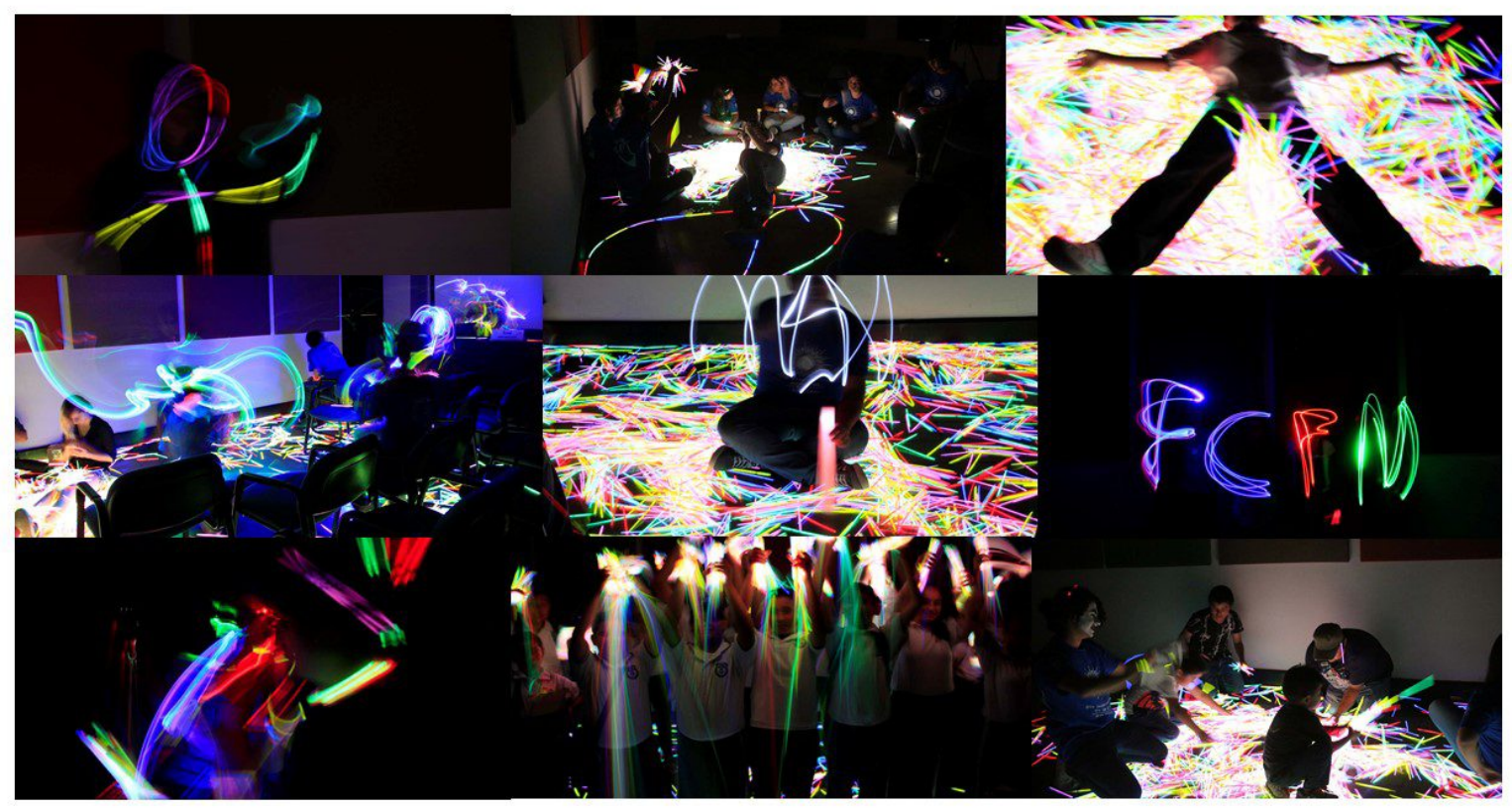

Figure 11. Light painting.
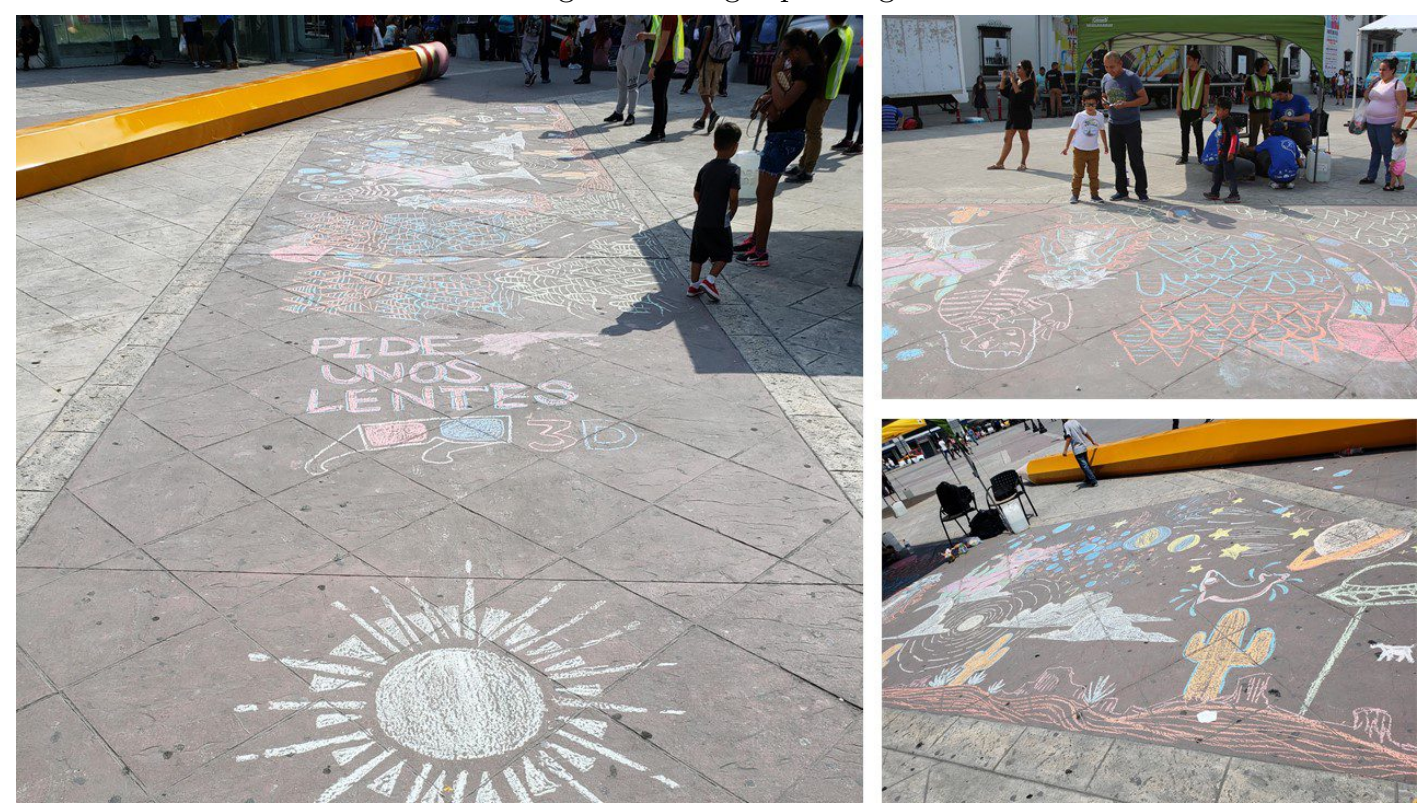

Figure 12. 3D illusions observed over a chalk paint commemorating the IDL and using chromatic aberration to create the 3D-effect.

Finally, to a complete experience related with science, the complementary science outreach activities by the "Divertimatematicas" and "Robotics FCFM - UANL" allowed the families and the public to learn that Math and Robotics are also science and learn it is also fun and exciting. 


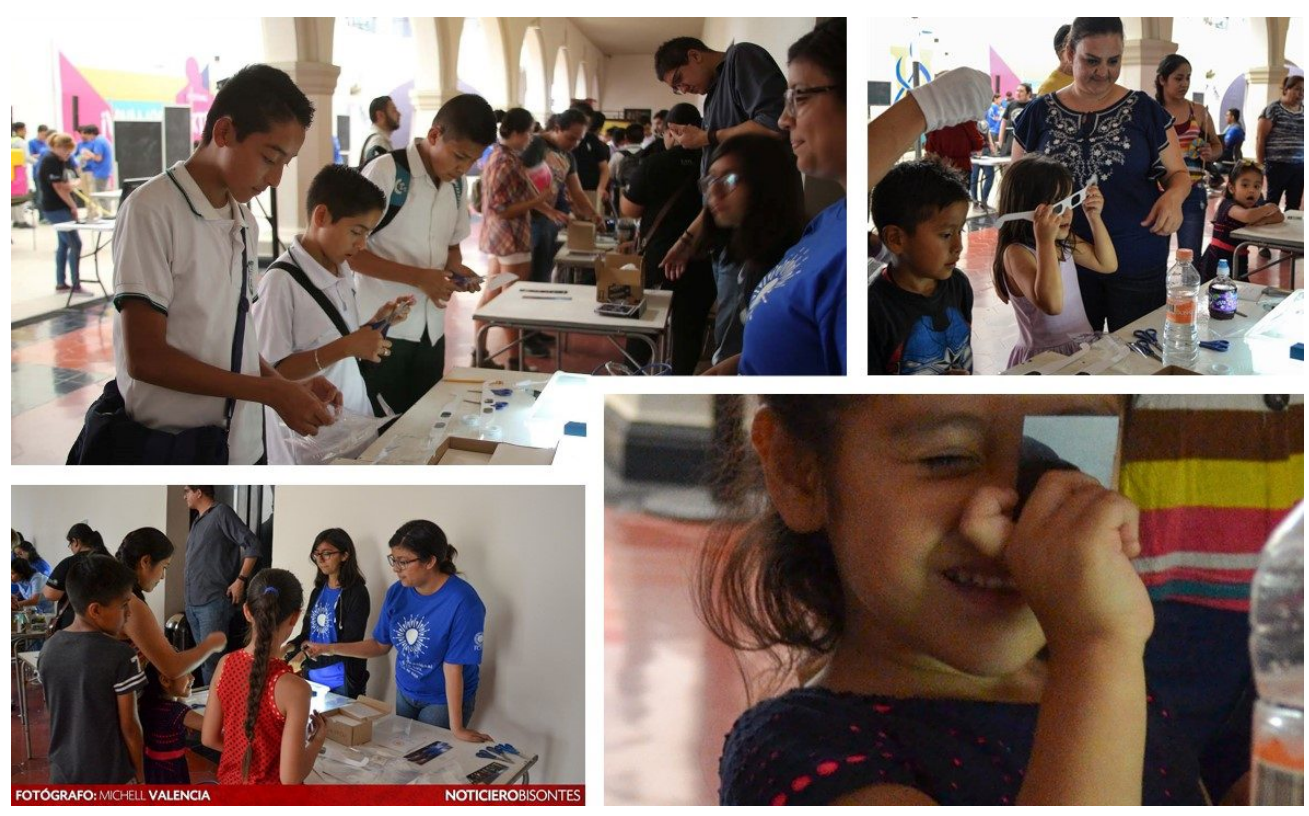

Figure 13. Polarized art demonstration. It tas a very successful activity due to the beauty of polarized light.

\subsubsection{Outcomes}

It was a 6 hours event that offered more than 3 hours of different activities where kids, teenagers, adults, whole families and the general public could participate an learn about how light affects our lives in different fields. The main results obtained were:

- Many people could not associate the concept of art with science and, thanks to the event, they learned that it is possible to combine the two fields.

- Part of the success of the activities was to play with the capacity of amazement of the audience.

- For all the activities it was critical to let the audience to think what they were observing and why was happening but, most important, never underestimate or criticize an answer, so hey can find out by themselves if their theories were or not correct.

- The activities that most engaged the public were the ones using art, but it was mandatory to explain the science aspect of each one, to create the link between hard science and art.

- The use of a comic play to make aware of the importance of light was a handy resource because the public said it was easy to identify themselves with the characters and understand the main message of the play.

- The use of plushies to interact with small kids and explain to them the life of a scientist was a good and enjoyable approach.

- The most successful activity according to the interest of the public was the Light painting activity, but it was the most difficult of control and, in some cases, the awareness about Science was not achieved.

- According to the expected learning outcomes, the hands-on activity of kaleidoscope (Fig. 14)and the art demonstration of polarizing art were the most successful, especially when the public participated in the science interactive demonstrations before.

- The science demonstrations related to astronomy were some of the favorites of the public, and it does not have complications to engage the public although not include much interaction, it is due to the amazing that is the Astronomy. 
- In public events, it is important to add activities that can catch the attention of the pedestrians as the mimes, the complementary science activities and the face painting.

- Add the word "free" to the advertising is very useful to involve more people.

- Thanks to the advertising of the event, we even received a school group during the event.
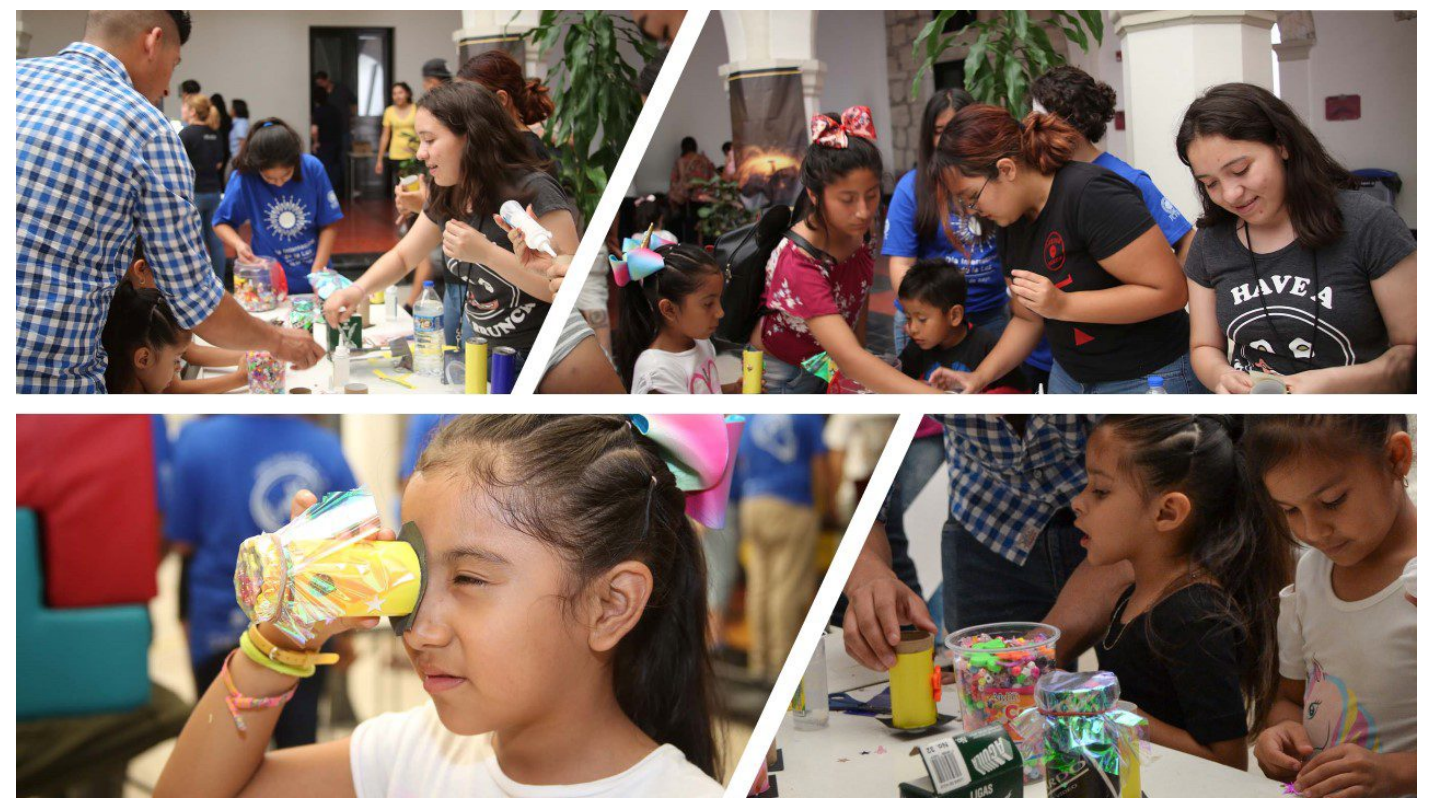

Figure 14. Kaleidoscope hands-on activity. It was constructed 100 kaleidoscopes during the event.

\section{CONCLUSIONS}

During this full-day project, more than 100 volunteers helped in the attention of 1240 persons, including the 40 elementary and secondary school teachers and the 1200 people that participated in the public event. It represents a 4 and a half hours workshop for the teachers and a 6 hours public event with around 4 hours of content that were planned and organized for more than six months, including the advertising since January 2018.

The Mexican science curricula for elementary and secondary school does not include much content about Optics and Photonics but, thanks to the workshop "Dumpster Optics", the teachers understood that Light, Optics and Photonics could be used for teaching different topics in Science, Math and Art.

Although 4 and a half hours are not enough to cover the "Dumpster Optics" material, the teachers learned the basic concepts about light and how to include experiments in their everyday lessons in the classroom. In fact, thanks to this workshop, a new project has begun, the formal adaptation of the "Dumpster Optics" booklet to the science curricula, where the Science, Math and Art lessons and grades will be highlighted to help the teachers to include these materials during the elementary and secondary school grades.

The public event "Suma Ciencia - IDL in Monterrey" was successful because it involves families; thus, the process of learning science was improved thanks of the interaction of the families, because the kids that enjoyed something try to explain it to their parents, enforcing the concepts learning.

The artistic activities allowed the public to understand that the light is fun and they can play with it but, with the scientific activities, they also learned that light is useful and vital for life and technology, accomplish with this one of the goals of the IDL.

We can conclude that the project "IDL in Monterrey: science, art and culture of light" is one of the most successful one-day outreach events performed outreach groups of the Facultad de Ciencias Fisico Matematicas of 
the Universidad Autonoma de Nuevo Leon, not only by the numbers of volunteers of the number of people that attended, also because it represented a big effort where different groups worked together to celebrate a scientific "holiday".

\section{ACKNOWLEDGMENTS}

We want to thank all the groups involved that worked very hard to accomplish all the goals of this project:

- UANL Mobile Planetarium

- Cultura UANL

- Laniakea

- Divertimatematicas

- Robotics FCFM - UANL

- Laboratorio Kabblam FCFM

- CAD FCFM

- Make-up and especial effects Student Club

- IEEE Photonics Society UANL Student Chapter

- SEP N. L.

- SPIE-OSA ITESM Student Chapter

- Recreacion en Cadena

- Quark

The event "Suma Ciencia" is supported by the National Council of Science and Technology (CONACyT). Special thanks to Judy, Nancy and Kathleen for allow us to be part of the "Dumpster Optics" project.

The project "IDL in Monterrey" was supported by the SPIE IDL Micro Grant and the project "Optics for everyone" was supported by the SPIE Education Outreach Grant 2017. Thanks SPIE to allow us to make this happen!

\section{REFERENCES}

[1] "International day of light - background and goals." https://www.lightday.org/ (2018). Accessed: 201807-20.

[2] Perla M. Viera-González, G. E. S.-G., "Optics 4 every1, the hands-on optics outreach program of the universidad autonoma de nuevo leon," Proc.SPIE 9946, 9946 - 9946 - 11 (2016).

[3] "Dumpsters optics - teaching and learning optics without a kit." http://www.lasertechonline.org/ Dumpster_Optics.html (2018). Accessed: 2018-01-20.

[4] "Recreación en cadena, red mexicana de talleristas de ciencia." http://recreacionencadena.com (2018). Accessed: 2018-01-20.

[5] "Outreach merriam-webster.com." https://www.merriam-webster.com/dictionary/outreach (2018). Accessed: 2018-07-20.

[6] Varner, J., "Scientific outreach: toward effective public engagement with biological science," BioScience 64(4), 333-340 (2014).

[7] GONZLEZ-ARANGO, C. M., La Enseñanza de la Óptica desde una conceptualizacin integradora de sus teorías, dinamizada y orientada por una concepción del aprendizaje significativo crítico, $\mathrm{PhD}$ thesis, Universidad Nacional de Colombia (2013). 
[8] Vergara Marn, D. P., Estudio del impacto didctico de la metodologa "De aprendizaje activo" en la enseanza de la ptica, PhD thesis, Universidad Nacional de Colombia, Sede Medelln (2012).

[9] "Demonstration merriam-webster.com." https://www.merriam-webster.com/dictionary/ demonstration (2018). Accessed: 2018-07-20.

[10] "Hands-on merriam-webster.com." https://www.merriam-webster.com/dictionary/hands-on (2018). Accessed: 2018-07-20.

[11] Yakman, G. and Lee, H., "Exploring the exemplary steam education in the us as a practical educational framework for korea," Journal of the Korean Association for Science Education 32(6), 1072-1086 (2012).

[12] Judy Donnelly, Nancy Magnani, K. R., "Dumpster optics: teaching and learning optics without a kit," Proc.SPIE 9946, 9946 - 9946 - 7 (2016). 